\title{
Strategies for Developing Economy of Iran's Sports Industry
}

\author{
${ }^{1}$ Hamta Hadian*, ${ }^{2}$ Seyed Mohammad Hossein Razavi, ${ }^{3}$ Mohammad Reza Boroumand, \\ ${ }^{1}$ Saeed Amirnejad \\ ${ }^{1}$ Department of Sport Management, Faculty of Sport Sciences, Shomal University, Amol, Iran. ${ }^{2}$ Department \\ of Sport Management, Faculty of Sport Sciences, Mazandaran University, Babolsar, Iran. ${ }^{3}$ Department of \\ Sport Management, Faculty of Sport Sciences, Shahid Beheshti University, Tehran, Iran.
}

Submitted 26 August 2019; Accepted in final form 21 January 2020.

\begin{abstract}
Background. Currently, sports as a big industry is considered as one of the most effective economic sources in developed communities and one of the important indices of the development of countries. Objectives. The present study was conducted aimed to design a strategic model of Iran's sports industry economy. Methods. This study is a strategic one that has been conducted by mixed sequential exploratory method. Also, the main research method was based on quad triangulation. The statistical population of the study including stakeholders and experts in economy of sports and professors of physical education who are fully acquainted with sports and related industries was a total of $\mathrm{n}$ $=226$ participated in the study purposefully and accessible. The data were collected through library studies, review of documents and documents, review of scientific and specialized articles, review of archives of publications and media, interviews, open and closed questionnaires, as well as Delphi method. Then, the models obtained from Likert scale questionnaires were approved in three shifts between 100 selected first group samples with a return of between 53 and 67 responses at each stage. Structural equation modeling was used by software PLS 3 to confirm the results. SWOT analysis was used to develop the strategies. Results. The factors affecting the economy of Iran's sports industry were identified and confirmed in the form of 11 strengths, 14 opportunities, 26 weaknesses and 24 threats. Then, by reviewing and analyzing the factor load, 25 appropriate executive strategies were developed and presented. Conclusion. According to the results, sports industry trustees, by forming a team of experts, put the proposed strategies of this study on the agenda, formulate the necessary executive plans, and then apply the necessary measures to implement the plan. The achievements of this study, using micro and macroeconomic planning can be the key to the non-growth of GDP of Iran and similar countries.
\end{abstract}

KEYWORDS: SWOT, Sports Industry, Economy, Strategic Plan.

\section{INTRODUCTION}

Today, commercialization and professionalization of sports industry, which has economic and social effects at the international level, has led to the development of the sports sector as a highly competitive profitable industry. Sports industry is one of the most important bases for economic development and social advance, and has played an exciting and important role in the sports economy and even the growth of the national economy. Sports industry is the emergence of a modern human economy in the form of a new industrial economy, one of the most diverse industries in the world of trade, and economically, one of the important factors of the regeneration of the national economy in many countries (1). Currently, sport as a large industry is one of the most effective economic resources in developed communities and is considered as one

*. Corresponding Author:

Hamta Hadian, Ph.D

E-mail: hamtahadian82@gmail.com 
of the important indices of the development of countries (2). According to Khorshidi and Shahbazi (2010), Moulin (1983) first mentioned sport as an industry. He believed that any amateur and professional sports activity that provided added value to sports goods and services could be called sports industry (3). Many countries, including the United States, Australia, Korea, Germany, the United Kingdom and other pioneers in this field, by segmenting their sports industry and separating economic and income-generating areas in sports, have analyzed its dimensions in depth and taking into account the strengths, weaknesses, opportunities and threats ahead for short-term and long-term planning that we are witnessing today in the economic development of their sports industry, and this investment and strategic planning has played a major role in the national economy of these countries (4). In the world of sports, most research projects on "Sports for Development" Sport-For-Development (SFD) have been conducted in Africa, Asia and Latin America. While 90\% of the study's authors are in North America, Europe and Australia. The study results show that the development of management and leadership in sports and entrepreneurship industry; and design thinking in affiliated companies to make the most of the industry's potential in a creative and sustainable way are among the strategies that the leading countries in the industry pursue are looking for $(5,6)$. $\mathrm{R}$ and $\mathrm{B}$ (2016) attributed the financial success of European elite clubs to the attention of the managers of these institutions to compensate for the income, achieve the maximum profit with their special attention to the brand and increase the special value of the club brand as well as short and long-term effects of private investment on the sports institutions (7). Accordingly, sport is a long-term investment whose effect on growth and development has been proven to everyone. 3.7\% of Europe's GDP comes from sports; about 15 million persons in various sectors of the industry are involved in sports, and the share of sports in employment is $2.12 \%$, which is comparable to the major industries in the union (Sports Econ Austria) (8). Meanwhile, the general economic effect of sports in Dubai until 1970 was $\$ 670$ million (9). Outdoor sports and recreation are also a large and important part of the US economy, with \$ 646 million in direct investment (US Open Industry Association, 2012). According to Gholamzadeh (2016), since 2002 to 2011, sports industry in Finland accounted for on average $1.45 \%$ of value added and $1.31 \%$ of GDP. According to the London 2012 and 2016 Rio Olympics financial reports, this major sports event was a solution to save the host countries from recession. Sports investments include $\$ 4.58$ million of Melbourne Formula One racing. The event grossed \$ 62 million and created 400 fulltime jobs, but in fact this phenomenon caused a dramatic \$ 60.5 million drop in other parts of Australia, indicating a total of $\$ 1.9$ million of gross domestic product in Australia as a whole is significant (10). Fakhri (2017) in a study acknowledged that the largest share of GDP in sports was produced by Hong Kong trading companies in the global market for sports goods. These activities directly contribute $\$ 9$ billion to Hong Kong's GDP per year. While the share of sports in Iran's GDP is only $0.7 \%$ Iran's share of sports exports over the past decade has been about $0.06 \%$ of the country's GDP, and the share of sports in world trade has been only $2.5 \%$. These figures are far from similar ones in countries such as the United States, the United Kingdom, Germany, China, Italy, and other countries that have dominated the largest sports industry market (11) (Asgarian, 2014). Also, the import of \$ 114.93 million of Iranian sports in 2011 was close to $0.14 \%$ of total import and $0.019 \%$ of GDP. This figure for 2015 is about $0.15 \%$ of total imports and $0.02 \%$ of GDP, which shows negative growth. In terms of exports, negative growth of $30.2 \%$ has been seen (12).

Undoubtedly, strategic planning is an important element for excellence and an essential tool for the effectiveness and sustainability of an organization (13). Strategic planning enables an organization to tailor its activities and services to the changing needs of the environment. This planning not only provides a framework for improving the plan, but also provides a framework for changing the structure of plans, management and collaboration, as well as evaluating the progress of the organization (14). The sports industry is no exception. The most important reason for the abandonment of Iran's sports industry is the lack of a comprehensive analysis of the factors affecting the backwardness of sports industry in Iran and lack of awareness and knowledge of sports managers and government officials about the existing potentials and opportunities and problems and challenges facing the country's sports industry. While, the 
perspective for government development plans does not address this problem as an incomegenerating industry. Therefore, in order to facilitate the comprehensive planning process of economic development of Iranian sports and related industries, the research team intends to identify the strengths, opportunities and obstacles in this path and provide appropriate executive strategies to advance the development objectives of Iran's sports economy. By properly recognizing and resolving environmental threats using applicable strategies, the economic potentials of Iran's sports industry can flourish and using this primary platform, the growth and development of Iran's sports industry and subsequent national economy can be achieved.

\section{MATERIALS AND METHODS}

According to the subject and objectives, the present study method is a strategic and field one, which was conducted in the form of a survey by descriptive-analytical method and is considered as one of the applied-developmental research. According to Delphi's research method and triangulation in this research, first with literature review such as books, papers, research treatises and projects, media programs and participating in various conferences (in the field of economics, sports, sports industry, Sports Economics and other related cases) the main research factors were extracted and then in person and virtual interviews were conducted with statistical samples (experts) by Delphi method.

Regarding the nature of the research and the need to collect data from different fields, the statistical population along with the number of samples and sampling method were defined as the following Table. Accordingly, the statistical population, including stakeholders and experts, economy and sports experts, and professors of physical education who are fully acquainted with sports and related industries were selected in several groups.

Those who participated in the study as a statistical sample were $n=226$ described in Table 1;

Group 1: $\mathrm{n}=83$ participated in the interviews. According to the interviews, information were obtained about sports industry, its infrastructure, views on the segmentation of the industry, and the opportunities and challenges ahead.

Group 2: The researcher-made questionnaires were distributed three times among 100 selected candidates of the first group on Likert scale in 3 turns and confirmed by 53 to 67 responses at each stage.

Also, the five-member research team consisted of the paper researchers, economy and sports marketing experts.

Table 1. Statistical Population and Sampling Method

\begin{tabular}{lcc}
\hline Group & Sampling & Sample \\
\hline $\begin{array}{l}\text { Human community } \\
\text { Managers and executives of responsible } \\
\text { organizations }\end{array}$ & Non-randomly convenience purposeful & 53 \\
University professors and experts & Purposeful and snowball & 73 \\
Sports entrepreneurs and business owners & Non-randomly convenience purposeful & 43 \\
Merchants of sports products & Non-randomly convenience purposeful & 49 \\
Sports market experts and consultants & Purposeful and snowball & 8 \\
\hline
\end{tabular}

With Group 1 of statistical population, the environmental factors of the sports industry, and the opportunities and challenges facing were identified by an economic approach. After the theoretical saturation and thematic classification of the results according to the nature of SWOT with the opinion of the research team, and removal of repeated cases, the necessary cases were integrated and corrected. Then, the final questionnaire was compiled, and provided to Group 2 online. By software PLS3, factor analysis was performed. In the inferential statistics section, factor load and the impact factor obtained were used to prioritize and rank the research factors. In the following, for development of strategies, SWOT analysis and strategic meetings were performed and during several stages, 32 final strategies were approved by the research team and provided to 35 Iranian planning experts for approval as a form. The final model was approved with 25 strategies by posttest.

\section{RESULTS}

Economic Perspective of Iran's Sports Industry. Economic development of Iran's sports industry and achieving optimal growth (more than $2 \%$ of Iran's gross domestic product) by 2025 
Effective Driving Factors (Strengths and Opportunities) on Economy of Iran's Sports Industry. Among 135 economic strengths and opportunities identified and extracted from interviews with experts and in-depth and longterm research studies, after repeated reviews and corrections, integration and removal of unnecessary items, the most important positive and driving factors of the economy of Iran's sports industry was tested with 11 strengths and 14 opportunities.

Strengths (S).

1. Growth of the share of sports in the Iranian economy in recent years

2. Existence of Iranian clubs in Asia for economic exploitation

3. Popularity of sports brands among the people

4. Existence of 72,000 young and talented graduates in the sports industry

5. Communicating the law of attraction and protection of foreign investment

6. Existence of fields for establishing specialized agencies for support, transfer of players and tourism

7. Existence of more than 18,000 registered sports clubs in Iran

8. Unique charm of the sport and the high volume of fans and contacts

9. Increase media revenue through sports advertising

10. Instant growth and development of sports software

11. Multifaceted nature of sports industry makes it possible for dependent industries to emerge for economic development.

Opportunities (O).

1. General popularity of the Iranian people for the activities of sports clubs and teams in Iran

2. Possibility of explaining the components of development in the sports economy

3. Awareness of the leaders of sports organizations to the bright future of the sports industry

4. Existence of natural potentials for holding events, hosting and attracting sports tourists

5. High interest and talent of student teams to create sports startups

6. Development of ICT and communication infrastructure and emergence of new technologies in Iran in recent years

7. Increased public interest in sports due to the prevalence of obesity, Diabetes, and etc., especially in the elderly and women
8. Growth of sports culture in Iranian families, especially their investment in sports for their children

9. Emergence of radio and television news programs and networks in the field of sports and sports economy

10. Continuous presence of journalists and increasing the supervisory role of classes of community on the performance of public and professional championship sports

11. Multiplicity of cheap work labor in the manufacturing sector

12. Ability to start an Internet business affiliated with the sports industry

13. Emergence of new data security systems such as Block Chain

14. Growth of public awareness and tendency to use social networks and online shopping sites

Impact Factor (Weaknesses and Threats)

Affecting the Economy of Iran's Sports Industry. Among 113 identified economic weaknesses and threats, the most important economic barriers to Iran's sports industry economy were tested in the form of 26 weaknesses and 24 threats.

Weaknesses (W).

1. Governmental structure of Iranian sports and its contradiction with the structure of federations

2. Lack of conditions for the presence of 18,000 clubs and affiliated complexes in the stock market

3. Lack of active presence of sports industry subsectors in the stock market

4. Unsuccessful implementation of private sector entering sports industry through the Privatization Organization

5. Incomplete protection laws in order to support the entry of the private sector into Iranian sports

6. Disruption of the professional club management system in Iran

7. Lack of knowledge of economics and income generation based on centralized and nonspecialized management

8. Lack of robust rules in the economic situation of Iranian sports

9. Significance of lack of a comprehensive plan of economic development of Iran's sports industry

10. Lack of a certain trustee in the structure of the country's sports to lead the economy of Iran's sports industry 
11. Abandonment of the production and distribution sector in sports-related industries

12. Lack of awareness of sports industry activists to develop and strengthen the subject of branding

13. Lack of appropriate database of the activities of sports industry activists

14. Lack of necessary training in the field of sports economics

15. Lack of professional qualification system for sports industry professional jobs

16. Lack of specialized sports academies

17. Lack of a formal job classification system in sports industry

18. Low credit and lack of a financial resource in sports institutions

19. Lack of specialized marketing and employment agencies and lack of hiring skilled human resources, which has led to inefficiency of commercialization of sports industry

20. Loss of Iranian clubs due to lack of proper management and economic planning and foresight

21. Proprietary instead of privatization due to political rents

22. Lack of strategic document of a comprehensive system of financial and economic development in the sub-sectors of sports industry, including clubs, products, and etc.

23. Lack of cost-benefit logic in various fields of sports industry such as media, tourists, club management and etc.

24 . Less hiring of young managers with creativity and pristine thinking, income generation and business specialties in sports industry

25. Lack of proper management and procedure to attract, retain and increase the number of fans of clubs or brands in sports industry

26. Lack of quality of computer and software knowledge among the majority of students and graduates of physical education

Threats (T).

1. Too much distance between sports clubs and institutions and global standards in the financial field

2. Lack of special facilities for the private sector by the government and affiliated organizations

3. Lack of economic stability in Iran and investment risk in sports industry

4. Lack of clear rules to encourage the private sector to invest in sports
5. Lack of independent trade unions of institutions and companies in sports industry

6. Lack of specialized centers of sports economy and the rupture of its commercialization rings

7. Exploiting the region and neighboring countries for the growth and development of sports industry

8. Media's attention and coverage to professional sports only as news

9. Interference of policy-making institutions in Iranian sports and lack of unity of decisionmaking

10. Lack of rule for resolving barriers for sports industry

11. Introducing sports industry in Iran as a purely social and cultural category

12. Excess import of foreign sports goods to Iran

13. General trend towards foreign brands

14. Non-economic view of government officials on the country's sports

15. Hidden monopolies and lack of transparency in pricing and providing certain financial information

16. Lack of specialized institutions in the field of privatization of sports industry

17. Existence of structural and cultural constraints to host international events and the lack of growth of its economic consequences

18. Illegal copying and lack of identity and authenticity of goods and services in the country and the entry of low-quality smuggled goods into the domestic market

19. Introversion and non-interaction with global markets in the country's economy

20. Pressure and negative impact of economic sanctions on the economy of various sectors of Iran's sports industry

21. Lack of a competitive structure in the country's economy

22. Non-compliance with copyright, registration and trademark rights in Iran

23. Significant distance between new technologies in Iran's sports industry and developed countries

24. Lack of direct access to sites and some social networks in Iran (filtering)

Confirmatory factor analysis was used to finally confirm the identified items and check the reliability and fit of the model. As shown in Figures 1 and 2, the coefficients of the factor load and the value of t-test indicate the validity and importance of each of the items. 


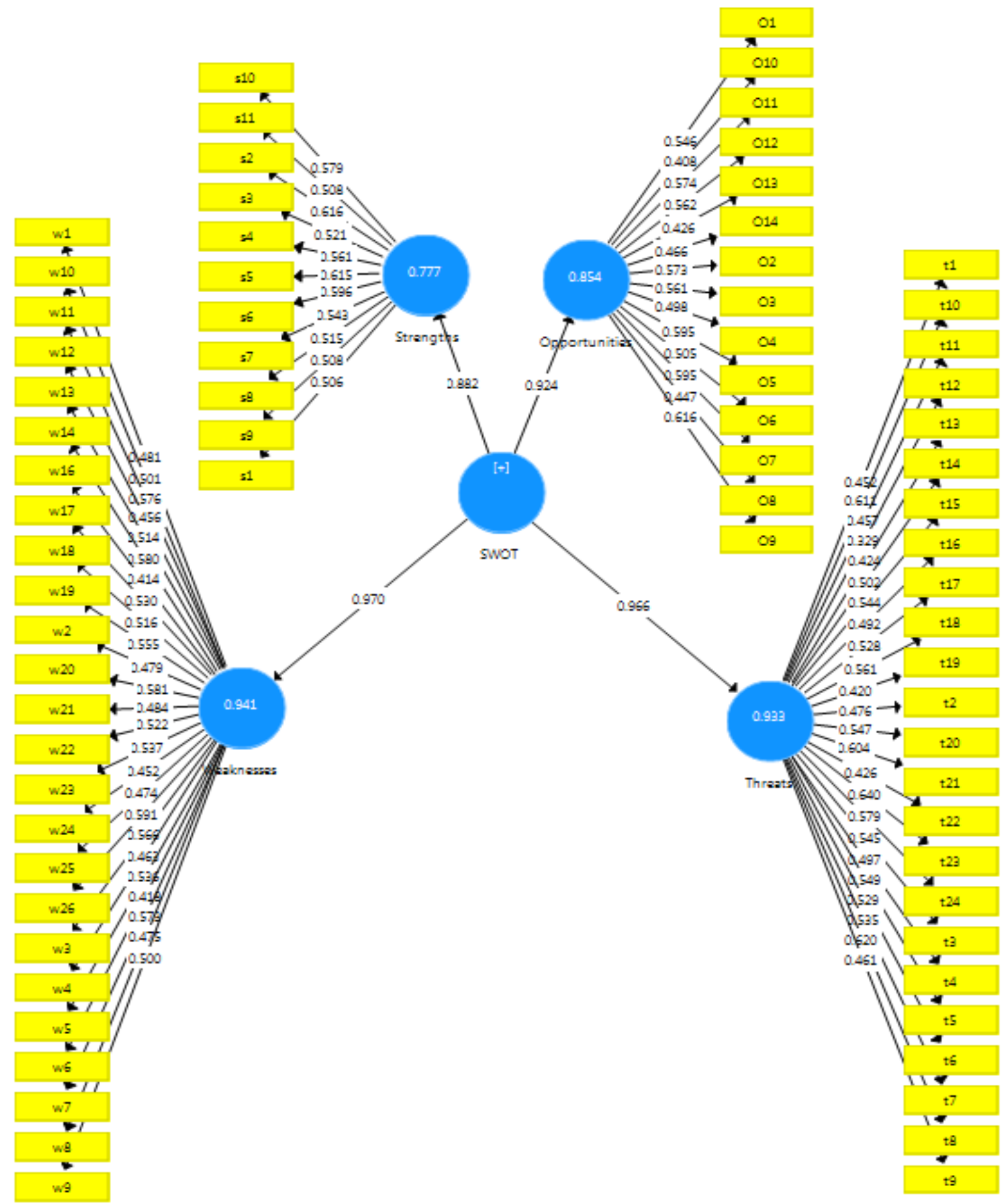

Figure 1. Research Model Tested in Standard State

According to Figures 1 and 2, the factor load less than 0.4 , the significant number and value of T-item "Media attention and coverage to professional sports only in the news aspect" is removed with a factor load of 0.322 , but the effect of the rest of items on the economy of Iran's sports industry is confirmed. Considering the value of $\mathrm{T}$ statistics in Figure 2, which was more than 1.96, the effect of all factors was significant. 


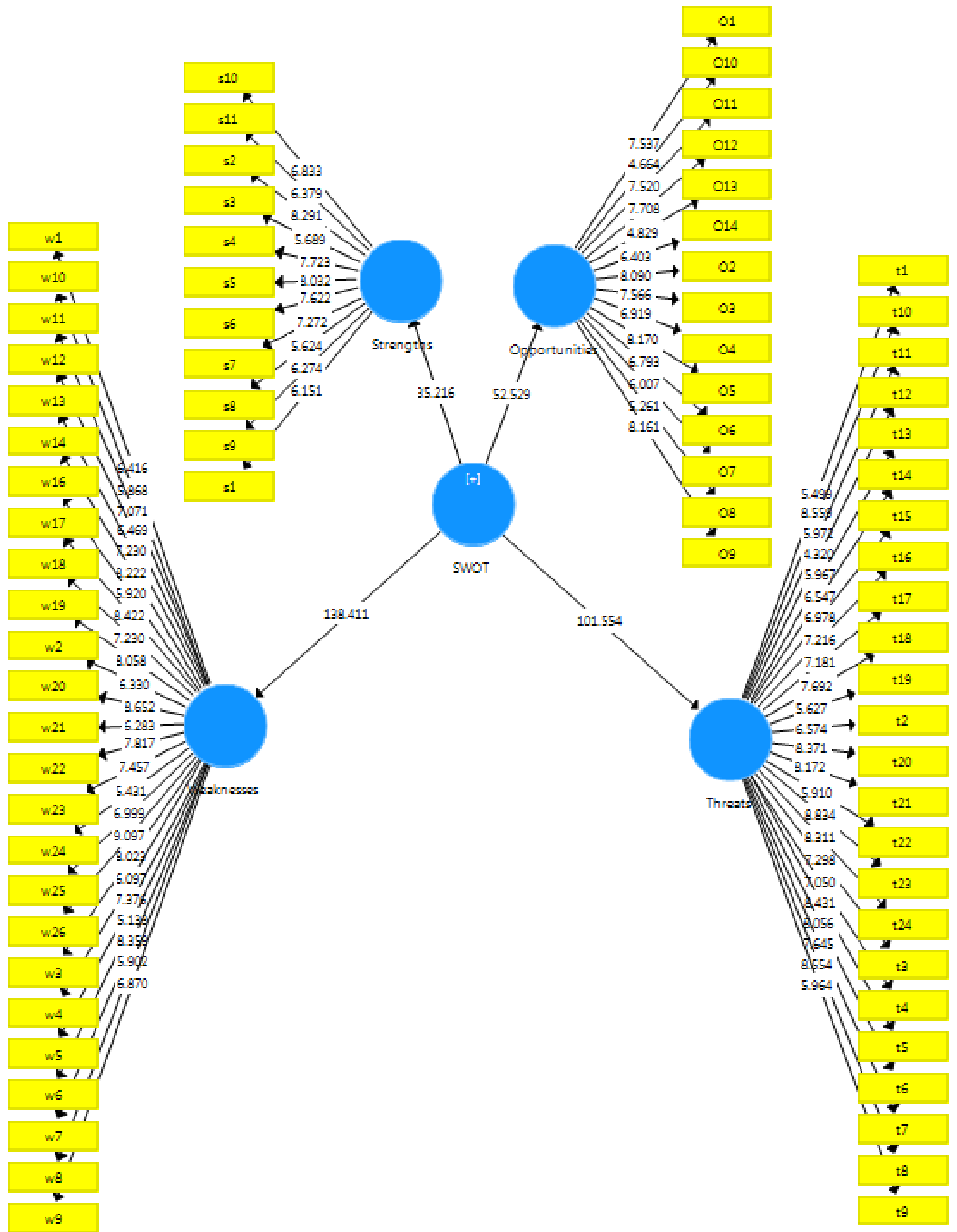

Figure 2. Research Model Tested as Significant Numbers

Reliability. The reliability of the structures was examined by Cronbach's alpha coefficient and Dillon-Goldstein coefficient (composite coefficient) and the acceptable value for these coefficients is at least 0.7. As shown in Table 2, Cronbach's alpha values and composite reliability 
of all the data obtained has been more than 0.7 , and this indicates the appropriate reliability of the research items and variables.

Table 2. Structure Reliability

\begin{tabular}{lcc}
\hline & $\begin{array}{c}\text { Cronbach's } \\
\text { alpha }\end{array}$ & $\begin{array}{c}\text { Composite } \\
\text { reliability }\end{array}$ \\
\hline Strengths & 0.806 & 0.819 \\
Opportunities & 0.798 & 0.804 \\
Weaknesses & 0.882 & 0.899 \\
Threats & 0.879 & 0.896 \\
\hline
\end{tabular}

Strategic Position and Action Evaluation Matrix (SPACEM). As shown in Figure 3, Iran's sports industry is in the worst possible position in strategic position and action evaluation matrix. In other words, it indicates the fact that in spite of internal weaknesses, it also faces numerous and major external threats; therefore, in order to develop a strategy, it is necessary to emphasize defensive and preventive strategies to change direction and improve the current position. It should be noted that the current position does not mean that the position of the economic dimensions of sports industry is limited to one of the houses of this model (defensive), but the value of SWOT analysis is that by comprehensive understanding of a position, the necessary strategies are set from other houses as well. For this reason, in the present study, all four positions have been considered, but with more emphasis on WTs.

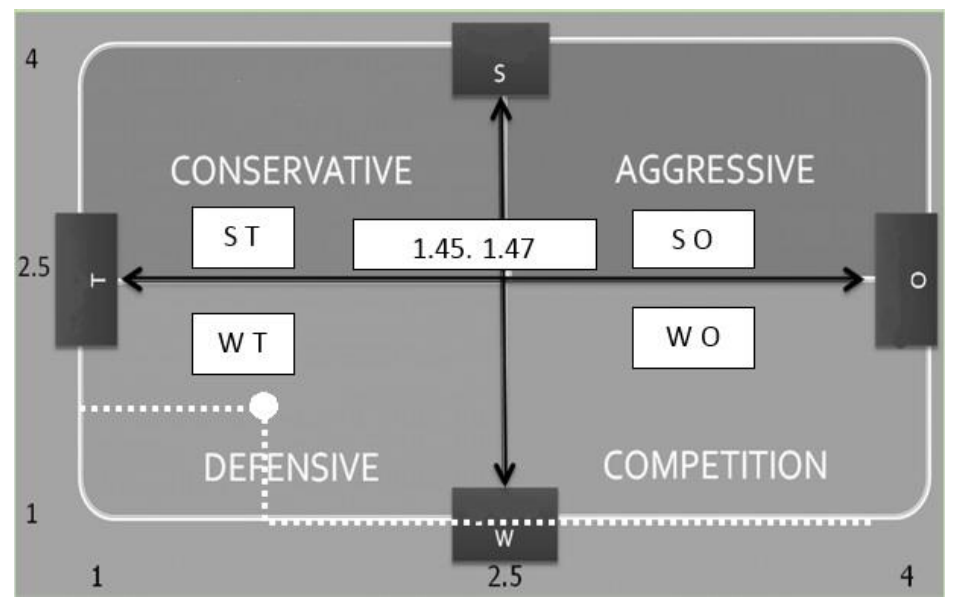

Figure 3. Strategic Position and Action Evaluation Matrix of Iran's Sports Industry

\section{Executive Strategies for Economic Growth} and Development of Iran's Sports Industry. Taking into account the segmentation of Iran's sports industry and effective economic factors and examining the influential internal and external factors on this industry, among 32 strategies proposed by the research team and accompanying professors, 25 strategies were approved as the final strategic model of Iran's sports industry economy.

SO Strategies. In SWOT matrix, the most desired position of an organization is that strategies seek to use the strengths of the organization and take advantage of the opportunities ahead to achieve a more desired position. In this regard, the system can identify its weaknesses and try to resolve them and turn them into strengths. This position is also called an aggressive position.

1. Growth of economic companies and marketing in the sports industry:
S1, S2, S3, S7, S11, O1, O2, O3, O4, O12, $\mathrm{O} 14, \mathrm{O} 15$

2. Create strong brands in sports industry and strive to increase brand equity:

S2, S3, S5, S6, S7, S8, S11, O2, O8, O9, O11, $\mathrm{O} 14, \mathrm{O} 16$

3. Strengthen the quality control and monitoring system to collect edits and disseminate sports industry news and programs:

S9, O10, O11, O16

4. Develop a regular organizational structure for fans:

S2, S3, S6, S9, S8, O1, O8, O9, O11, O16

ST Strategies. In this position, the organization tries to take advantage of the internal strengths of the organization by using appropriate executive strategies and minimize the threats and turn them into opportunities. This position is also called the conservative state matrix.

1. Development of commercial and commercial institutions in the sports industry: 
S2, S3, S6, S7, T1, T21, T19

2. Follow up and pass the media broadcasting law: S3, S8, S9, T8

3. Take appropriate measures to address structural and cultural constraints on sporting events in order to host: S3, S2, S8, T2, T9

4. Hold specialized meetings with economic leaders and entrepreneurs in sports industry to provide and train new activists entering this field:

S4, S11, T3, T6, T8, T11, T24

5. Hold and develop training and justification courses for stakeholders and economic working groups of sports industries:

S4, S6, S10, S11, T6, T7, T11, T14

WO Strategies. In this position, the organization tries to achieve the desired objectives by minimizing the weaknesses and making the best use of the opportunities. This position is also called the competitive position matrix. Usually, the strategies offered to improve the quality of the organization compared to competitors fall into this category.

1. Increasing the credibility and brand of clubs and production institutions:

W1, W2, W3, W4, W19, W20, W24, O1, O8, O9, 016

2. Creating suitable grounds for attracting young professionals in the body of Iran's sports industry: W6, W11, W14, W16, W18, W23, O6, O14

3. Develop appropriate policies and plans at the macro level of Iranian sports:

W1, W2, W5, W8, W13, W14, W15, O2, O3, O5, O7, O14

4. Benefit from the experiences of successful countries in the development of sports industry by conducting comparative studies:

W5, W11, W15, W19, W20, W21, O2, O3, O5, O7, O13, O14, O15

WT Strategies. This position of SWOT matrix can be considered as the most critical for the organization. In this position, the organization takes a defensive state and tries to minimize the weaknesses and modify the external threats using the relevant executive strategies to the extent that restructuring, re-evaluation, reduction in activities, removal of the organization or its integration with other organizations can be included in these strategies.
1. Develop a comprehensive economic development plan for Iran's sports industry: W3, W7, W8, W9, W10, W14, W21, T6, T7, T19, T20, T21, T23

2. Reduce bureaucracy and unnecessary regulations:

W1, W3, W4, W7, W9, T4, T5, T9, T10

3. Increase appropriate facilities for investment in Iran's sports industry:

W4, W16, W17, T2, T3, T4, T5, T6, T14

4. Increase micro and macro tax exemptions for sports industry activists:

$\mathrm{W} 4, \mathrm{~T} 2, \mathrm{~T} 4$

5. Development of coherent laws to ensure the rights of registration and copyright:

W4, W7, W9, W12, W20, T18, T22

6. Develop trade unions to support and supervise all subdivisions:

W1, W9, W10, W12, W16, T5, T6, T9, T16

7. Maintain greater coordination among decisionmaking bodies in sports industry:

W1, W6, W9, W14, T9, T11

8. Pass a law on removing barriers to production in the country's civil structure:

W10, T10

9. Supervise and pay more attention to the infrastructure of sports places and the quality of equipment and manufactured goods:

W3, W5, W11, W17, W22, W24, T1, T5, T18, T19, T21, T23

10. Trust and reduce investment insecurity by enacting required laws:

W4, W7, W17, W20, T2, T3, T4, T5, T12, T15, T20

11. Control and supervise rules to further depoliticize sports industry:

W1, W9, W11, T5, T9, T14, T15, T16, T17

12. Supervise the principle of meritocracy in the appointment system of sports managers and trustees:

W1, W6, W13, W14, W23, T6, T9, T14, T15

For the final approval of the strategies developed by the Strategic Council and the research team for the reliability and fit of the model, confirmatory factor analysis was used.

As shown in Figure 3, factor load coefficients show that factor load of SO5, ST6, and WO5-9 strategies was less than 0.4. Therefore, only 25 strategies were finally approved (Figures 4 and 5). 


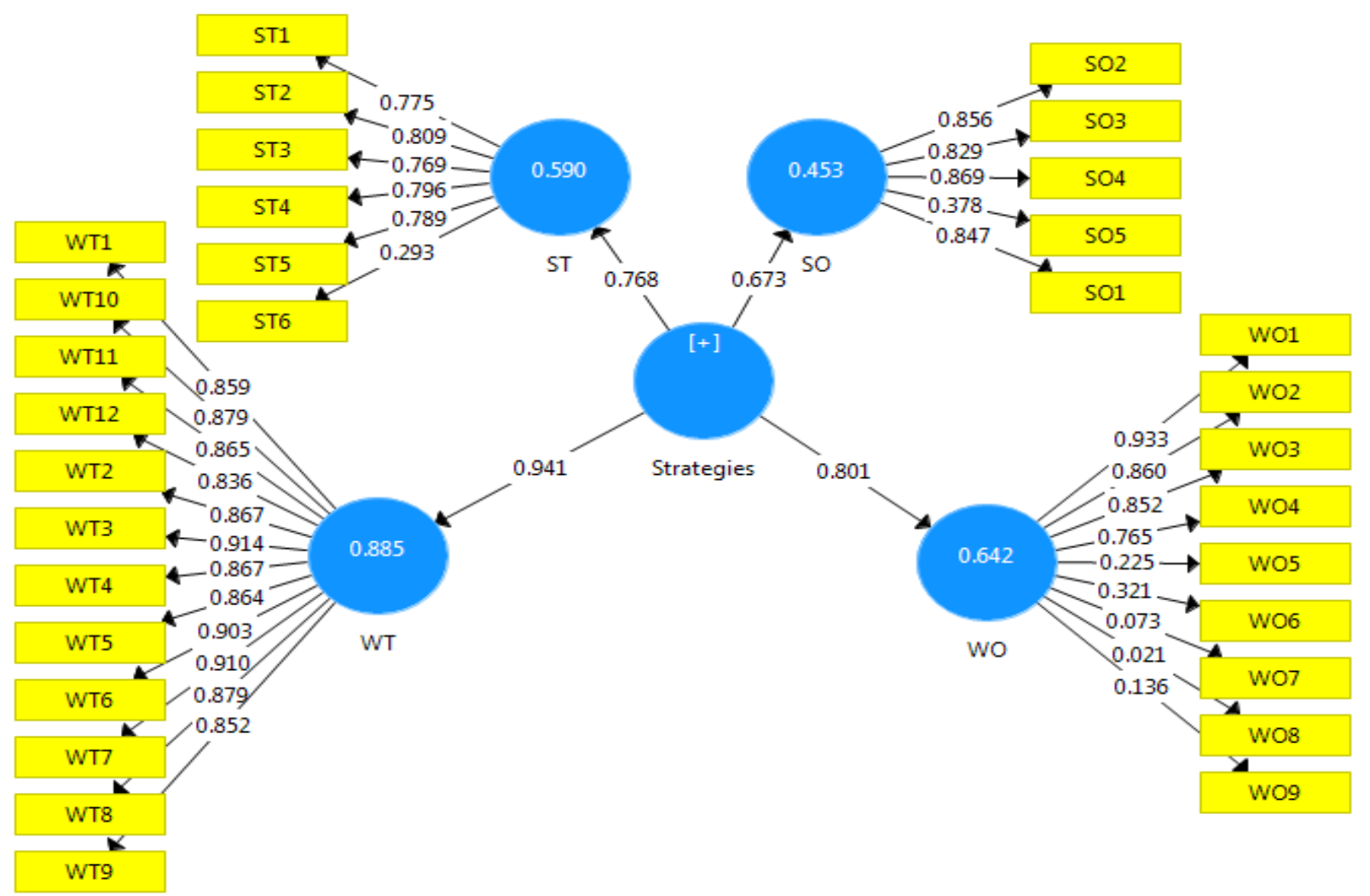

Figure 4. Research Model Tested in Standard State

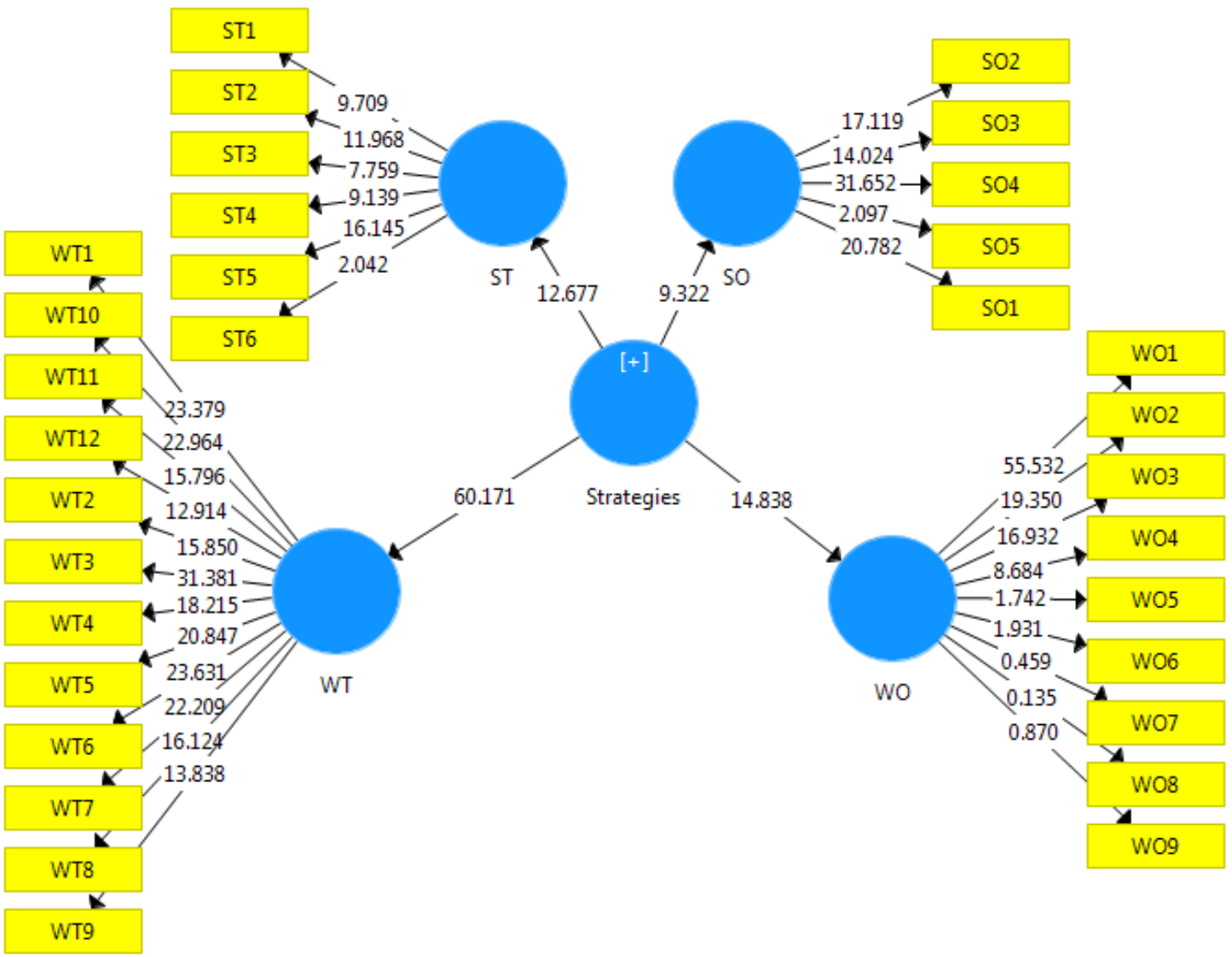

Figure 5. Research Model Tested as Significant Numbers 
According to Figure 5, the value of T statistics for the developed strategies, which was more than 1.96, indicates the significant effect of the strategies and other strategies whose $\mathrm{T}$ statistics were less were removed.

Reliability. The reliability of the structures was examined by two coefficients of Cronbach's alpha and Dillon-Goldstein coefficient (composite coefficient) and the acceptable value for these coefficients is at least 0.7. As shown in Table 3, values of Cronbach's alpha and composite reliability of all the data obtained have been more than 0.7, and this indicates the appropriate reliability of the research items and variables.

Table 3 Structure reliability

\begin{tabular}{lcc}
\hline & Cronbach's alpha & $\begin{array}{c}\text { Composite } \\
\text { reliability }\end{array}$ \\
\hline SO & 0.787 & 0.796 \\
ST & 0.806 & 0.834 \\
WO & 0.795 & 0.813 \\
WT & 0.849 & 0.865 \\
\hline
\end{tabular}

\section{DISCUSSION}

The present study was conducted to design a strategic model of Iran's sports industry economy. According to the results of the first part and during the field research, the factors affecting this industry were identified and confirmed with an economic approach in the form of 11 strengths, 14 opportunities, 26 weaknesses and 24 threats. Then, by examining and analyzing the factors of SWOT, in the second part of the research, executive strategies (25 strategies) were developed and proposed for the economic growth and development of Iran's sports industry.

Since sport, as a major industry, is considered as one of the most important indices of the development of countries, in any country that has the potential to grow in this field, having a comprehensive economic development plan for sports industry is a prerequisite for macro planning (WT1). Regarding the growing share of sports in the Iranian economy in recent years and the many potentials for the growth and development of this industry, such as 72,000 young and talented graduates in the field of sports, there are more than 18,000 sports clubs registered in Iran as a very important economic firm, more importantly, the multifaceted context of the sports industry that makes it possible for related industries to emerge. Also, by taking advantage of the opportunities identified in this study, such as the possibility of explaining the components of development in the sports economy, the leaders of sports organizations to economic development in sports industry, increasing the attention of people to sports to prevent all kinds of diseases and obesity, and the possibility of emergence of new businesses through the Internet and social networks, by developing a comprehensive economic development plan of Iran's sports industry can overcome many identified and existing weaknesses, and minimize threats, and subsequently macro and correct planning will lead to the growth and development of the national economy. The results of this strategy have been consistent with the study results of $S$ and F (2020); Sajadi et al. (2019); Hadian et al. (2018); and Christine and A (2018) (2, 15-17). The factors identified in the study, which were in the field of marketing and development of economic infrastructure and privatization, are strategies of growth of economic and marketing firms in sports industry; creation of strong brands in sports industry, efforts to increase brand equity; development of commercial institutions in sports industry, specialized meetings with economic leaders and entrepreneurs, increasing the credibility and brand of clubs and production institutions, increasing investment facilities, and increasing tax exemptions at micro and macro levels. In this regard, R (2016) has emphasized the link between marketing and industry in sports industry. He has focused on production, tourism, education and technology sectors in sports as the industry's economic development strategies (18). Consistent with the results of this section, $\mathrm{P}$ et al. (2018); Hadian (2018); R and B (2016) and Matthew (2016) all considered it important to invest in private companies and sports brand development, emphasized growth in the development of marketing and business companies in new areas of sports and saw these platforms as a great opportunity to attract and generate capital $(2,7,19,20)$. Soleiman et al. (2020) also considered strategic planning, organization, implementation and monitoring of the correct implementation of strategies as one of the strategies for sports development (21).

Regarding the great economic effects of sports such as household spending, contributing to the health economy, employment, tourism and export and import industries, growth of sports media, advertising and attracting financial sponsors, 
private sector investment, stock market participation, and many social and political effects that have many economic consequences, including the reduction in crime and the increase in the country's national image in the region and international arenas, show the importance of appropriate strategies for economic development of sports industry (22). The attention of developed sports countries such as the United States, Australia, Korea, Germany, and the United Kingdom to short and long-term planning has led to the economic development of their sports industry, which has a major share of the national economy (4).

Analyzing the factors identified in the study provided elements such as the multifaceted nature of sports industry, the possibility of the emergence of dependent industries; the possibility of explaining the components of development in sports economy; existence of natural potentials for holding events and hosting and attracting sports tourists; increasing public interest in sports due to the prevalence of obesity, Diabetes, and etc., incompleteness of protectionist laws in order to protect the entry of the private sector; the lack of use of economic knowledge and income generation; the abandonment of the production and distribution sector; the lack of specialized marketing and employment agencies; lack of cost-benefit logic in different areas of sports industry, existence of structural and cultural limitations for hosting international events and the lack of growth of its economic consequences; introversion and lack of interaction with global markets in the country's economy; and strategies such as developing a regular organizational structure for fans; taking appropriate policies and plans at the macro level of Iran's sports; benefiting from the experiences of successful countries for developing sports industry by conducting comparative studies; increasing appropriate facilities for investment in Iran's sports industry; monitoring and paying more attention to the infrastructure of sports places and quality of equipment and goods produced, trust and reduced investment insecurity through the enactment of required laws. In this regard, studies on the effect of sports infrastructure have shown that the existence of sports places had a positive effect on the region's economy and led to economic prosperity in the region (2). F and $\mathrm{H}$ (2018) considered sports places as effective on local and national economy
(23). H et al. (2018) conducted a study on the effect of the share of public sports facilities on the social health of people in North Korea and concluded that the number and quality of public sports facilities and, of course, fair distribution of facilities in all parts of the country are essential priorities of governments in their development plans because raising nutrition and social health levels and reducing health care costs can affect the economic income of people and the country (24). Meanwhile, Christine and A (2018) in their study on the safety and quality of sports halls and their surroundings, considered investing in the growth and development of sports infrastructure, increasing quality of sports facilities and equipment, media advertising in this field, more control and supervision for maintenance of highquality sports places, improving the quality of sports organizations, access to sports places and facilities for the public and fans, and well-defined planning for the well-being of sports consumers (17). L (2016) considered international exchange and economy and tourism infrastructure development in the field of sports as an important factor in social development and economic growth in Shanghai (25). K stated that investing in international events would have a direct and indirect effect on the local and national economy, as well as social behavior and household spending in the host region, with positive results and a positive impact on gross domestic product (26). Although the events have a positive effect on the host region, in many cases, such as the 2013 World Cup in Norway, events such as ski jumping, despite the significant number of spectators contributed to the positive economic effects of the host region, there were millions of NOKs that were less than expected (27). Chung et al. studied elite economic and sports activists in the East Asian Games on the direct economic consequences of spending on the host (28). Kim et al. attributed the increase in non-local and international participants to an increase in the economic effect of events on the host city and related industries, including production (29). A and $\mathrm{R}$ examined the causes of the positive economic effects of some sports compared to others, calling small events more profitable for the region (30). All of the above studies emphasized the direct and indirect effects of sports industry on the national economy and the growth and development of the host and individual and social health. 
Consistent with other proposed strategies in this study, Sajadi et al. (2019) in environmental analysis of marketing of the Iranian Badminton Premier League considered the optimal use of human resources and new facilities and technologies, attracting financial sponsors and reducing government ownership as the most important factors in economic development of Iran's sports industry (16). A similar study was conducted on strategies for developing sports industry in Indonesia. Due to the lack of good educational facilities and programs in Indonesia, it has been proven that industrialization of sports has been a way to overcome problems at the top of management plans. In this study, the quality and reasonable prices of products in Indonesia in the field of sports products and export opportunities to emerging markets such as South Africa, Egypt and the United States; limited capital and poor branding for domestic brands, illegal copying by competitors and inability to compete with the global market were among the factors identified in the environmental analysis of the industry in Indonesia. Gaining market opportunities and increasing market share in sports industry; attracting educated and elite human resources in order to attract new science and technology in sports; reducing the problems of entrepreneurs in sports and marketing industry, developing national sports and creating a culture of sports with an emphasis on healthy lifestyle in Indonesia, focus on international sports competitions and increase the level of domestic competition and hosting major events, tourism objectives and focus on sports tourists, and increasing the synergy of the sports industry with other industries through the printed, electronic and social media are the most important strategies suggested for the country's plans (31), which is consistent with many of research objectives and strategies. One of the most important parts of the sports industry is the attention to the fans, which can greatly affect any of the sub-sectors of the industry, including production, products, and advertising and the market. Organizing this section included the important strategies of this study, which requires more communication between clubs, teams, brands, officials and managers of Iranian sports with the fans. In this regard, $\mathrm{C}$ et al. in their study on sports fans emphasized the need for the interaction between sports teams and community and maintaining and supporting fans as undeniable assets for the survival of clubs and sports teams to create added value in sports industry (32). Among the elements affecting the economy, the role of sports brokers and marketers is not hidden from anyone. In this regard, B and K (2017) examined the role of sports brokers, club transfers and bargaining power at different levels and economic benefits. The results showed that elite players and, in fact, the superstars, using the new structure of the sports markets, have the right to bargain for themselves and their salaries, while the players at the moderate level are under control of their clubs and contracts and have a smaller share of this market (33). S (2018) considered companies' reliance on imported products, lack of attention to domestic production, predicting future demand with a focus on the consumer value, analyzing sales markets to attract customers to sports industry, focusing on creative economic ecosystems for the needs of Korean elderly population and increasing focus on the sporting goods industry as ways to prepare for the Fourth Industrial Revolution for Korea (34). Also, the results of parts of the study were consistent with the study results of W (2019) and $\mathrm{H}$ (2018) (35, 36).

\section{CONCLUSION}

All 25 strategies proposed in this study could be executive suggestions for Iran's economic development authorities. One of the most important is the development of a comprehensive economic development plan for Iran's sports industry, which can resolve many identified and existing weaknesses and minimize threats and then macro and correct planning in this regard will bring growth and development of the national economy. Also, no serious measure was taken to identify the opportunities, challenges and obstacles of Iran's sports economy, and its lack was seen at all levels of sports planning in the country. Designing a strategic model of Iran's sports industry economy can be an effective and efficient step for the development of this incomegenerating and money-making platform. For this purpose, the trustees of sports industry, including the Ministry of Sports and Youth and the Ministry of Industry, Mines and Trade, should form a team consisting of research and sports economy experts who have the necessary skills in this field. Then, include economic development factors of sports industry in the agenda, analyze various dimensions, develop the necessary executive 
plans, and finally make the necessary arrangements to implement the plan.

Finally, this document is a good source for researchers and sports and economic planners. Filling the gaps in Iran's sports economy and helping to resolve existing barriers using proposed solutions is a complete scientific and executive resource for planners and managers of Iran's sports industry and the Ministry of Sports. Also, the achievements of this research, using micro and macroeconomic planning, can fill the gap of the non-growth of the gross national product of Iran and similar countries.

\section{APPLICABLE REMARKS}

- Establishment of the Iranian Sports Industry Academy as the trustee of specialized training

- Recognition of the country's sports system

- Effective and friendly communication between industry and academia

- Reform regulations and updating unnecessary rules for sports businesses

- Facilitate the issuance of licenses for the establishment, construction or renewal of contracts and licenses

- Establishment of scientific institutes and associations and knowledge-based companies in order to develop economy and marketing of sports industry

- Support domestic sports brands, manufacturers and service providers

- Increase private property rights
- Localization of successful experiences of leading countries for the development of Iran's sports industry

- Development and growth of transnational businesses

- Target large international markets

- Entry of sports industry sub-sectors into the stock market and competitive market space

- Brand registration and identity

- Join the World Intellectual Property Organization and remove its monopoly and government rents

- Analyze the opportunities and challenges of sports industry to help plan at the macro level

- Efforts to recognize sports industry as a complete and independent industry in the Ministry of Industries and Mines

- Remove barriers to gender discrimination in sports such as women's entering stadiums

- Remove barriers to broadcasting TV competitions

- Develop a comprehensive plan for meritocracy and empowerment of managers and employees of sports industry

- Systematize sports media

- Form trade unions as the trustee

- Increase political diplomacy in order to promote the country's sports industry through the Ministry of Foreign Affairs

\section{ACKNOWLEDJMENT}

I would like to express my deepest appreciation to dear Masoud Najafi. Clearly this huge search and survey could not have been implemented without his proper support and helpful guide.

\section{REFERENCES}

1. H. GF. Sport as an industry in finland-exploring the economic significance, contributions, and development of the sport sector as an industry. Academic Dissertation Publicl Discussed Permission Faculty Sport Health Sci Univ Jyväskylä. 2016.

2. Hadian H, Razavi SMH, Boroumand MR, Amirnejad S. Segmentation of Iran's sprts industry in economic perspective. Örgütsel Davranış Araştırmaları Dergisi. 2018;3:129-147.

3. Khorshidi A, Shahbazi M. Study of relationship between sports and economy.: Office of Cultural Studies (Department of Youth and Physical Education), Research Center of Islamic Consultative Assembly of Iran; 2010.

4. Basten S, Cuaresma JC. Modelling the macroeconomic impact of future trajectories of educational development in least developed countries. Int J Educat Develop. 2014;36:44-50. doi: 10.1016/j.ijedudev.2013.12.003

5. Schulenkorf N. Managing sport-for-development: Reflections and outlook. Sport Manage Rev. 2016;20(3):243251. doi: 10.1016/j.smr.2016.11.003

6. Nico S, Emma S, Katie R. Sport for development: An integrated literature review. J Sport Manage. 2016;30(1):2239. doi: $10.1123 / \mathrm{jsm} .2014-0263$

7. Rohde M, Breuer C. The financial impact of (foreign) private investors on team investments and profits in professional football: Empirical evidence from the premier league. Appl Economic Finance. 2016;3(2):243-255. doi: 10.11114/aef.v3i2.1366

8. SPEA. Study on the contribution of sportto economic growth and employment in the EU.: Study commissioned by the European Commission, Directorate-General Education and Culture.; 2012.

9. Group SB. Economic impact of sport in Dubai. In: council Ds, editor. Dubai2015. 
10. Dwyer L, Jago L, Forsyth P. Economic evaluation of special events: Reconciling economic impact and cost-benefit analysis. Scandinavian J Hospitality Tourism. 2016;16(2):115-129. doi: 10.1080/15022250.2015.1116404

11. Fakhri F. Design of the factors influencing the share of sport products in foreign trade of the country [Phd Tesis]. Field SM, editor. Iran,Bablsar: Mazandaran University; 2017.

12. Asgarian F, Jafari A. Economic investigation of sport expenditures of the Iranian households during 1998 - 2001. Quarter J Sport Sci Res. 2007;18:75-86.

13. Gomes Teixeira GF, Canciglieri Junior O. How to make strategic planning for corporate sustainability? J Cleaner Product. 2019;230:1421-1431. doi: 10.1016/j.jclepro.2019.05.063

14. Namada J, Bagire V, Aosa E, Awino Z. Strategic planning systems and firm performance in the export processing zones. American J Indust Business Manage. 2017;7:487-500. doi: 10.4236/ajibm.2017.74035

15. Sandelin J, Fiechtner J. Selection process of sport tourism development strategy in Banja Vrućica SPA resort: A quantitative analysis. J Sport Sci Nutrition. 2020;1(1):11-18.

16. Sajjadi SN, Rajabi H, Hamidi M, Hajizadeh A. SWOT analysis of the marketing of badminton premier league of Islamic Republic of Iran. Sport TK. 2019;8(1):107-114. doi: 10.6018/sportk.362161

17. Christian E, Obiora O. On-field sports spectatorship and patronage: A sociological xray of its determinants for effective sports management in developing countries. British J Educat. 2018;6(2):84-93.

18. Ratten V. The dynamics of sport marketing: Suggestions for marketing intelligence and planning. Market Intelligence Plann. 2016;34(2):162-168. doi: 10.1108/MIP-07-2015-0131

19. Matthew B. Financial Management in the Sport Industry. 2nd, editor. New York Routledge2016.

20. Pouder R, DanaClark J, Fenich G. An exploratory study of how destination marketing organizations pursue the sports tourism market. J Destination Market Manage. 2018;9:184-193. doi: 10.1016/j.jdmm.2018.01.005

21. Sulaiman Khamidi A, E. M. The evaluation of athletic extracurricular management of Dr.Soetomo and Jalan Jawa Junior high school in Surabaya. Budapest Int Res Linguistic Educat Sci (BirLE). 2020;3(1):11-19. doi: 10.33258/birle.v3i1.748

22. Rostamzadeh P, Sadeghi H, Asari A, Yavari K. Government investment in sports sector on economic growth in Iran economics. Sustainable Growth Develop. 2014;15(4):177-210.

23. Feng X, Humphreys B. Assessing the economic impact of sports facilities on residential property values: A spatial hedonic approach. J Sport Economic. 2018;19(2):188-210. doi: 10.1177/1527002515622318

24. Han EJ, Kang K, Sohn SY. Spatial association of public sports facilities with body mass index in Korea. Geospat Health. 2018;13(1):542. doi: 10.4081/gh.2018.542 http://ncbi.nlm.nih.gov/pubmed/29772876

25. Liu D. Social impact of major sports events perceived by host community. Int J Sport Market Sponsorship. 2016;17(1):78-91. doi: 10.1108/IJSMS-02-2016-005

26. Kwiatkowski G. Economic impact of event attendees' spending on a host region: A review of the research. Event Manage. 2016;20(4):501-515. doi: 10.3727/152599516X14745497664398

27. Kwiatkowski G, Oklevik O. Primary economic impact of small-scale sports events. Event Manage. 2017;21(3):269-280. doi: 10.3727/152599517X14942648527509

28. Cheung SY, Mak JY, Dixon AW. Elite active sport tourists: Economic impacts and perceptions of destination image. Event Manage. 2016;20(1):99-108. doi: 10.3727/152599516X14538326025198

29. Kim MK, Kim SK, Park JA, Carroll M, Yu JG, Na K. Measuring the economic impacts of major sports events: the case of formula one grand prix (F1). Asia Pacific J Tourism Res. 2017;22(1):64-73. doi: 10.1080/10941665.2016.1176061

30. Agha N. An explanation of economic impact: why positive impacts can exist for smaller sports. Sport Business Manage: An Int J. 2016;6(2):182-204. doi: 10.1108/SBM-07-2013-0020

31. Ahmad N, Mr S, Sigit N, Mr S, editors. Strategy of sport industry development as supporting tourism in DIY. 2nd Yogyakarta international seminar on health, physical education, and sport science (YISHPESS 2018) and 1st conference on interdisciplinary approach in sports (CoIS 2018). Atlantis Press; 2018.

32. Chae Rhee Y, Wong J, Kim Y. Becoming sport fans: Relative deprivation and social identity. Int J Business Administ. 2017;8(1):118-134. doi: 10.5430/ijba.v8n1p118

33. Brocard JF, Cavagnac M. Who should pay the sports agent's commission? An economic analysis of setting the legal rules in the regulation of matchmakers. Int J Sport Finance. 2017;12(1):65-88.

34. Seo E. A study on the constraints and the solutions in silver sport industry sociology study. 2018;8(3):146-155. doi: $10.17265 / 2159-5526 / 2018.03 .005$

35. Willem A, Girginov V, Toohey K. Governing bodies of sport as knowledge brokers in Sport-for-All communities of practice. Sport Manage Rev. 2019;22(5):584-599. doi: 10.1016/j.smr.2018.08.005

36. Hambrick ME, Svensson PG, Kang S. Using social network analysis to investigate interorganizational relationships and capacity building within a sport for development coalition. Sport Manage Rev. 2019;22(5):708-723. doi: 10.1016/j.smr.2018.12.002 